\title{
DIREITO À PRIVACIDADE NO SISTEMA REGIONAL EUROPEU DE DIREITOS HUMANOS
}

\author{
RIGHT TO PRIVACY IN THE AND EUROPEAN REGIONAL SYSTEM OF HUMAN RIGHTS
}

\section{Leonardo Stoll de Morais}

Mestre em Direito Mestre em Direito pelo Centro Universitário Ritter dos Reis. Bacharel em Direito pelo mesmo centro. Professor de Direito Civil IV (Direitos Reais) e de Direito Civil V (Direito de Família e Sucessões) na

Universidade Federal de Pelotas. Professor de Teoria Geral do Direito Civil, e Metodologia no Programa de Pósgraduação Lato Sensu em Direito Civil da Universidade Católica de Pelotas. Foi professor colaborador da disciplina de Direito Sanitário na Universidade Federal de Ciência e Saúde de Porto Alegre. É pesquisador do Laboratório de Pesquisa em Bioética e Ética na Ciência do Hospital de Clínicas de Porto Alegre-LAPEBEC/HCPA/UFRGS.

E-mail: leonardostollm@gmail.com

Recebido em: $14 / 04 / 2018$

Aprovado em: 06/08/2018

\begin{abstract}
RESUMO: O presente artigo fornece uma revisão jurisprudencial do direito à privacidade no sistema regional europeu de direitos humanos. Para isso, realizou-se uma pesquisa no site da Corte Europeia, com os descritores: privacidade; vida privada; vida familiar; domicílio; e correspondência. A partir desses termos, localizaram-se 22 (vinte e duas) decisões que dizem respeito à vida privada; 07 (sete) que versam sobre à vida familiar; 06 (seis) que estão relacionadas à proteção do domicílio; e 05 (cinco) que tratam da inviolabilidade da correspondência. Os casos foram reunidos para análise qualitativa de conteúdo. Como resultado, verificou-se que o termo vida privada é aplicado às situações jurídicas subjetivas envolvendo à identidade pessoal, à imagem, os dados pessoais e os dados sensíveis do indivíduo. Já o termo vida familiar compreende às situações associadas às relações formais e informais, às decisões reprodutivas e o controle do poder parental. Sobre o termo domicílio, a Corte considera que ele abrange a proteção da privacidade de pessoas situadas em albergues, estabelecimentos comerciais e a em suas residências. Por fim, o termo correspondência é aplicado em casos envolvendo manifestações escritas e orais, externadas por meio de cartas, e-mails, rede sociais e via telefone. Os resultados indicam que o tratamento conferido à privacidade pelo sistema regional europeu de direito humanos consolida o direito à autonomia dos indivíduos, marcando assim, o desenvolvimento da personalidade dos seres humanos, do ponto de vista individual e relacional.
\end{abstract}

Palavras-chave: Direito à privacidade; Sistema regional europeu de direitos humanos; Corte Europeia de direitos humanos.

\begin{abstract}
This article provides a jurisprudential review of the right to privacy in the European human rights regional system. To that end, a research was conducted on the European Court website, with the keywords: privacy; private life; familiar life; residence; and correspondence. From these terms, 22 (twenty-two) decisions were taken that relate to private life; 07 (seven) that deal with family life; 06 (six) that are related to the protection of the domicile; and 05 (five) dealing
\end{abstract}


with the inviolability of correspondence. The cases were pooled for qualitative content analysis. As a result, it has been found that the term private life is applied to subjective legal situations involving personal identity, image, personal data and sensitive data of the individual. The term family life includes situations associated with formal and informal relationships, reproductive decisions and control of parental power. Regarding the term domicile, the Court considers that it covers the protection of the privacy of people located in shelters, commercial establishments and in their homes. Finally, the term correspondence is applied in cases involving written and oral manifestations, expressed through letters, e-mails, social networks and via telephone. The results indicate that the treatment given to privacy by the European human rights regional system consolidates the individuals' right to autonomy, thus marking the development of the personality of human beings, from an individual and relational point of view.

Keywords: Right to Privacy; Regional Human Rights System; European Court of Human Rights.

SUMÁRIO: Introdução. 1. Premissas teóricas envolvendo o direito à privacidade; 2. Aplicação do direito à privacidade no sistema regional europeu de direitos humanos; 2.1 Vida privada e a proteção de situações jurídicas subjetivas de conteúdo individual; 2.2 Vida familiar, a correspondência, o domicílio e a proteção de situações jurídicas subjetivas de conteúdo relacional. Considerações finais. Referências.

\section{INTRODUÇÃO}

No cenário regional europeu de direitos humanos ${ }^{1-2}$, os direitos civis e políticos receberam importante atenção, principalmente na Convenção para a Proteção dos Direitos Humanos e das Liberdades Fundamentais. Nesse documento, os direitos fundamentais incluem a proteção à privacidade ( $\operatorname{artigo} 8^{\circ}$ ), de forma que qualquer pessoa tem direito ao respeito de sua vida privada, familiar, do seu domicílio e da sua correspondência, não podendo haver ingerência da autoridade pública no seu exercício, salvo nos casos previstos em lei ou quando constituir uma providência que afete direitos e liberdades de terceiros (Europe, 1950).

$\mathrm{O}$ direito à privacidade, no sistema regional europeu, é protegido por meio de quatro escopos que estão relacionados à vida privada, à vida familiar, o domicílio ou à correspondência do indivíduo. Tais termos são dotados de conteúdo jurídico indeterminado. Por esse motivo, a sua compreensão exige a análise de casos concretos.

Alinhando-se a essa necessidade, o presente artigo fornece uma revisão jurisprudencial sobre o direito à privacidade produzida no contexto regional do sistema europeu de direitos humanos. Para isso, realizou-se uma pesquisa com o objetivo de compreender às situações jurídicas

\footnotetext{
${ }^{1}$ Os sistemas regionais de direitos humanos são integrados pelos sistemas interamericano, europeu e africano. A sua incorporação à Organização das Nações Unidas (ONU) surgiu com o objetivo de compatibilizar compromissos globais com locais, conforme alcance geográfico de cada continente, ganhando dimensão o chamado glocal. Essa expressão é utilizada por Paul Soriano, por meio da leitura de Manuel Castells de que local significa os "nós" - nós de valor acrescentado aos fluxos econômicos e lugares de vida social Assim, no "glocal, " o "local" representaria os "nós" da rede global e integra as resistências, e as contribuições das formações identitárias locais e regionais na construção dos direitos humanos. Consultar: HABIBUL, Haque Khondker, "Glocalization as Globalization: Evolution of a Sociological Concept". Bangladesh e-Journal of Sociology. Vol. 1. No 2. Jul., 2004.

${ }^{2}$ O sistema europeu de proteção dos direitos humanos tem origem ao final da Segunda Guerra mundial. Nesse movimento, alguns Estados (Bélgica, Dinamarca, França, Holanda, Irlanda, Itália, Luxemburgo, Noruega, Reino Unido e Suécia) reuniram-se em Londres, em 5 de maio de 1949, para fundar o Conselho da Europa. Tal fato levou a elaboração da Convenção para a Proteção dos Direitos Humanos e das Liberdades Fundamentais de 1950. Para um estudo geral do sistema europeu, v. MAZZUOLI, Valério de Oliveira, Tratados internacionais dos Direitos Humanos, pp 984 a 1005, in Curso de Direito Internacional Público, $5^{\text {a }}$. edição, revista, atualizada e ampliada.
}

Revista de Direito Brasileira | Florianólopis, SC | v. 25 | n. 10 | p. 200-220 | Jan./Abr. 2020 


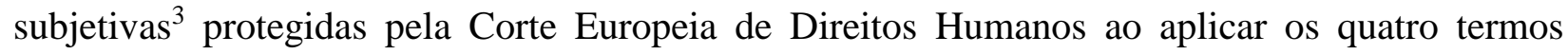
previstos no artigo $8^{\circ}$ da Convenção para a Proteção dos Direitos Humanos e das Liberdades Fundamentais.

$\mathrm{O}$ artigo segue organizado em duas partes: na primeira, demonstram-se às premissas teóricas que sustentam as definições e os contornos do direito à privacidade; na segunda parte, apresentam-se os resultados obtidos por meio da pesquisa jurisprudencial, a fim de promover uma discussão sobre às situações jurídicas subjetivas que são protegidas no sistema regional europeu de direitos humanos.

\section{PREMISSAS TEÓRICAS ENVOLVENDO O DIREITO À PRIVACIDADE}

O estudo do direito à privacidade pressupõe a compreensão dos contornos teóricos e das premissas que sustentam o uso da terminologia "vida privada". Esse entendimento, não se restringe a uma questão meramente formal de eleição de termos ou expressões, mas de um problema de representação de significado, principalmente porque no mundo jurídico o uso das palavras é determinante, na medida em que elas afirmam sentidos e produzem discursos.

$\mathrm{Na}$ literatura jurídica são apresentadas uma multifária de termos para representar, propriamente ou não, a palavra privacidade. A heterogeneidade fica evidente quando são apresentados os termos: vida privada, intimidade, segredo, sigilo, recato, reserva, intimidade da vida privada. Tais termos induzem os juristas a diversas possibilidades, sem, contudo, explicitar o real conteúdo do emprego das palavras utilizadas para sinalizar o direito em discussão.

A falta de uma definição unitária que reflita o conteúdo semântico do direito à privacidade é percebida inclusive nos enunciados normativos que visam sua tutela. No âmbito dos direitos humanos são utilizadas as expressões: vida privada, vida familiar, inviolabilidade do domicílio e da correspondência. No direito brasileiro, o artigo $5^{\circ}$, inc. X, da Constituição da República Federativa do Brasil de 1988 (CRFB/88) traz as expressões: vida privada, intimidade e domicílio. Em contraste, na jurisprudência brasileira ${ }^{4}$ e no sistema regional europeu e interamericano de direitos humanos encontramos o emprego da palavra privacidade.

É possível supor que as expressões são equivalentes? parte da Doutrina sustenta essa hipótese (DONEDA, 2006, p.111-2). Nesse caso, não teria problema usar qualquer uma das expressões para representar o mesmo direito tutelado. Contudo, há autores que sustentam que a palavra intimidade não se confunde com o termo vida privada, de forma que primeira significa algo mais restrito que a últimas. (SAMPAIO, 1998, p. 616; TÉRCIO SAMPAIO, 1993, p.79)

\footnotetext{
${ }^{3}$ As situações jurídicas estão no campo da eficácia. Quando certas consequências jurídicas se ligam a determinadas situações ou comportamentos, configuram-se as situações jurídicas. Por isso, os efeitos por excelência dos fatos jurídicos na ordem civil consistem nas situações jurídicas subjetivas. Tais efeitos, enquadráveis em categorias distintas estrutural e funcionalmente, podem ser reunidos sob a designação genérica de situações jurídicas subjetivas. Pouco importa se o conteúdo dessas situações foi previsto pelos próprios agentes que participaram do ato (no exercício de sua autonomia negocial) ou se resulta, em vez disso, da lei (como ocorre nos atos jurídicos stricto sensu, nos atos-fatos jurídicos e nos atos ilícitos). Sobre a qualificação funcional das situações jurídicas subjetivas, ver: Pietro PERLINGIERI: "toda situação é efeito de um fato, ou seja, encontra a sua origem em um fato, natural ou humano, juridicamente relevante” (O direito civil na legalidade constitucional. Rio de Janeiro: Renovar, 2008, p. 669). Assim, também, José de Oliveira ASCENSÃO: "A valoração jurídica dos casos concretos implica a produção de consequências jurídicas. Essas consequências jurídicas traduzem-se justamente na modelação de situações jurídicas”" (Direito Civil: Teoria Geral. Volume III: Relações e situações jurídicas. Coimbra: Coimbra Editora, 2002, p. 11).

${ }^{4}$ (1) BRASIL. Tribunal de Justiça do RS. Apelação Cível No 70061242012, Décima Câmara Cível, Julgado em 23/10/2014; (2) BRASIL. Tribunal de Justiça de SP. APELAÇÃO No: 1001989-76.2014.8.26.0020; Comarca: São Paulo; Órgão julgador: $7^{a}$ Câmara de Direito Privado; Data do julgamento: 12/08/2015; Data de registro: 12/08/2015; (3) BRASIL. Tribunal de Justiça de ES. APELAÇÃO: 3000288-85.2013.8.26.0180; Comarca: Espírito Santo do Pinhal; Órgão julgador: $2^{\text {a }}$ Câmara de Direito Privado; Data do julgamento: 10/03/2015; Data de registro: 13/03/2015; (4) BRASIL. Tribunal de Justiça de MG. APELAÇÃO: 0014233-69.2013.8.26.0576; Comarca: São José do Rio Preto; Órgão julgador: $1^{a}$ Câmara de Direito Privado; Data do julgamento: 10/03/2015; Data de registro: 10/03/2015;

Revista de Direito Brasileira | Florianólopis, SC | v. 25 | n. 10 | p. 200-220 | Jan./Abr. 2020
} 
Classicamente o uso do termo vida privada se refere à teoria dos círculos concêntricos de Hubmann $^{5}$, ou como denominada na literatura alemã, a teoria da cebola passiva (HERBERT 2000, p. 49). A teoria de Hubmann constitui de um importante modelo dogmático que contribuiu para elucidação de como aplicar o direito à privacidade em uma época que pouco se discutia sobre esse direito (HUBMANN, 1953).

Já o uso da palavra privacidade, enquanto direito subjetivo, tem origem em 1890, quando juristas norte-americanos Warren e Brandeis revisitaram o conceito jurídico de propriedade material para configurar evolutivamente o direito imaterial à privacidade. Os autores, através da linha interpretativa analógica e por meio de precedentes judiciais da Suprema Corte dos EUA, concluíram que havia um estatuto jurídico constitucional capaz de garantir o direito geral à privacidade como right to be left alone, conceituando-o como aquele que protege o direito de estar só do indivíduo, independentemente da forma de expressão - manifestos em cartas, diálogos, livros, desenhos, pinturas ou composições musicais (BRANDEIS, L. D.; WARREN, S. D, 1890).

Os modelos propostos na cultura jurídica alemã e norte-americana influenciaram as demais culturas jurídicas na proteção do direito à vida privada ou à privacidade. Entretanto, tais modelos dogmáticos foram revisitados e atualizados, principalmente em vista dos novos contornos sociais firmados a partir da construção histórica dos direitos humanos.

Em particular, na visão contemporânea o direito à privacidade decorre exclusivamente do livre desenvolvimento da personalidade da pessoa humana, visto que o simples fato de viver em sociedade já afasta, por si só, o anonimato. (CACHAPUZ, 2006, p. 53). Por esse motivo, todo ser humano possui originariamente direito à privacidade, de forma que ele se liga as condições de existência e de expressão à singularidade. Trata-se, assim, de um direito que tem substrato ontológico e histórico no desenvolvimento de ser, enquanto pessoa humana, bastando o fato de estar vivo para incorporá-lo no mundo jurídico (ASCENSÃO, 2010, p. 59).

Observa-se que o direito à privacidade, enquanto bem da personalidade humana é garantido à pessoa natural, concretizando o princípio da exclusividade. Essa perspectiva, foi formulada por Hannah Arendt com base nas definições de Kant, visando amparar a pessoa humana dos riscos oriundos da pressão social niveladora e da força do poder político ou de atores sociais (TÉRCIO SAMPAIO, 1993). Nessa visão, o direito à privacidade comportaria fundamentalmente três aspectos que garantem a exclusividade do indivíduo: "a solidão (desejo de estar só); o segredo (dever de confidencialidade ou sigilo) e a autonomia (liberdade de decidir sobre si mesmo como centro irradiador de informações). (TÉRCIO SAMPAIO, 1993)

Sobre o princípio da exclusividade, Maria Cláudia Cachapuz destaca que ele foi apresentado como elemento distintivo representando a "briga com o conformismo social", sendo capaz de possibilitar o resguardo daquilo que a pessoa tem como íntimo e privado, inclusive, sobre aspectos, que no âmbito público seriam motivo de discriminação. (CACHAPUZ, 2006, p. 123)

\footnotetext{
${ }^{5} \mathrm{O}$ autor alemão da obra Das Persönlichkeitsrecht, classificou o direito geral da personalidade em três círculos concêntricos (esfera secreta, íntima e privada) dentro dos quais se desdobraria a personalidade humana. Para o autor, tem-se como primeira e mais densa das esferas, a esfera do segredo (Geheims $\neg$ phäre) que garante a proteção absoluta dos indivíduos na sua própria pessoa, como por exemplo, as posições filosóficas, políticas, da orientação sexual, etc. Esta esfera constitui-se de âmbito do qual o indivíduo exerce total controle e poderá manter em total segredo fatos e informações da coletividade (HUBMANN, 1953, p. 30-40). A intimidade é definida pelo autor como a esfera intermediária (Vertrauens $\neg$ phäre), que engloba informações mais restritas sobre o ser humano, compartilhadas com reduzido número de pessoas que possuem relações familiares, afetivas e profissionais com o indivíduo ou com pessoas que têm acesso a informações de forma privilegiada em razão do status profissional (i.e, psicólogos, padres e advogados, profissionais de saúde, etc.). É neste círculo que se encontram protegidos o sigilo domiciliar, profissional e das comunicações telefônicas, que sofrem restrições mais agudas para sua abertura. Por último, o autor caracteriza a privacidade como parte da esfera da vida privada em sentido estrito (Privatsphäre), em que repousam as relações interpessoais menos densas, na qual não há um amplo grau de conhecimento da vida alheia. $\mathrm{O}$ acesso ao público, na esfera da vida privada, é apontado pelo autor como restrito, mas seu grau de adstrição é o menor dentre as três esferas, sendo o interesse público uma justificativa adequada, em alguns casos, para acesso e revelação de informações privadas. Ver: HUBMANN, Heinrich. Das persönlichkeitsrecht. Münster: Böhlau-Verlag, 1953, p. 30-40.
}

Revista de Direito Brasileira | Florianólopis, SC | v. 25 | n. 10 | p. 200-220 | Jan./Abr. 2020 
De qualquer forma, o princípio da exclusividade esculpido no direito à privacidade não é absoluto. Classificar o direito à privacidade com natureza de direito absoluto não é o mesmo que dizer que seu conteúdo seja. Isto porque o direito à privacidade atribui ao seu titular (pessoa humana) uma série de situações jurídicas subjetivas e existenciais, das quais recaem imediatamente sobre o bem jurídico tutelado (liberdade negativa). Tais situações jurídicas geram a todos os integrantes da sociedade um dever geral de abstenção, uma obrigação universal negativa. Desse modo, o direito à privacidade tem natureza de direito absoluto, no sentido de ser oponível e prevalente contra todos.

Consequentemente, a pessoa humana como ser singular é titular do direito à privacidade e poderá reivindicá-lo contra qualquer pessoa ou ente, no âmbito público e privado. Contudo, essa reivindicação deverá sempre observar os princípios gerais presentes nas relações jurídicas, e principalmente considerar o dever de solidariedade social, sob pena de legitimar um direito ao egoísmo (ASCENSÃO, 2010, pp. 97-98).

Nesse sentido, Doneda (2006) aponta que o direito à privacidade não se limita a tutelar o egoísmo ou afastamento completo da pessoa dos outros membros da sociedade. O autor utiliza a teoria relacional de Pietro Perlingieri ${ }^{6}$ para apresentar a privacidade a partir de uma relação jurídica, superando, assim, a tendência de encerrar o direito na construção dos institutos civilísticos em termos exclusivos de atribuição de direitos ou de poderes. Por isso, a perspectiva de Doneda não legitima a ideia de poder subjetivo de controlar à privacidade, mas a noção de tutelar cada interesse envolvendo a proteção desse direito através da análise da situação jurídica a ela contraposta.

A compreensão de que o direito à privacidade não se destina unicamente à satisfação de interesses, a todo custo, do seu titular abre margem a um amplo controle de abusividade e o reconhecimento de situações jurídicas subjetivas, norteadas pela ideia de cooperação necessária entre centros de interesse (SOUZA, 2014).

Em particular, nos sistemas regionais de direitos humanos, parte-se da compreensão de que o direito à privacidade protege situações jurídicas subjetivas existênciais, constituindo um bem tutelado pela personalidade humana, sendo mais abrangente que a proteção de círculos concêntricos, cerrados e limitados ou o direito de estar só ou o direito ser deixado em paz (CORTE EUROPEIA DE DIREITOS HUMANOS, 1974).

As situações jurídicas subjetivas envolvendo o direito à privacidade, podem ser caracterizadas como originárias e essenciais. Primeiramente, são originárias, na medida em que são adquiridas pelos seres humanos ao nascerem em uma sociedade, sem a necessidade de concurso de qualquer meio de aquisição ou pressuposto ulterior. Em seguimento, são essenciais, pois a privacidade é um direito imprescindível à própria personalidade e acompanha a pessoa natural por toda sua existência, inclusive, transcendendo a ideia de extinção com ocorrência da morte ${ }^{7}$ (AMARAL, Francisco, 2014, p. 304).

\footnotetext{
${ }^{6}$ Para PERLINGIERI, o direito civil é um sistema de relações e isso inclui o aspecto dinâmico, caracterizado pelo nascimento, a realização, a modificação e a extinção de relações jurídicas, isto é, o conjunto das suas vicissitudes" (O direito civil na legalidade constitucional, cit., pp. 728-729).

${ }^{7} \mathrm{~A}$ jurisprudência reconhece direito à privacidade de pessoa humana já falecida. Exemplificativamente, ver: BRASIL. TJ/SP. Apelação APL 10019897620148260020. 2015. Ementa: ALVARÁ JUDICIAL. LIBERAÇÃO DE PRONTUÁRIO MÉDICO DE PACIENTE FALECIDO AO FILHO. Sentença que extinguiu o processo sem julgamento de mérito por inépcia da inicial. Justificativa que, em verdade, se relaciona com falta de interesse de agir, já que se entendeu pela adequação de exibição de documentos para a hipótese. Exigência de autorização judicial pelo Hospital para liberação do prontuário de paciente falecido. Exercício regular de direito. Orientação do Conselho Federal da Medicina (Parecer CFM n ${ }^{\circ}$ 6/10). Imposição de observância das normas administrativas da entidade de classe pela Lei 3.268 /57. Precedentes. Procedimento de alvará adequado. Desnecessidade de participação do nosocômio na causa. Ilegitimidade passiva reconhecida. Petição inicial apta. Interesse de agir comprovado por documentos. Prontuário solicitado pela operadora do plano de saúde da falecida para análise de reembolso. Prudente a intervenção do Ministério Público. Direitos de privacidade de pessoa já falecida em ação proposta por seu filho. Interpretação do art. 82 , I e II , do CPC . Art. 1.105 do CPC . Sentença anulada para determinar o regular prosseguimento do feito. Recurso provido. (grifou-se)
}

Revista de Direito Brasileira | Florianólopis, SC | v. 25 | n. 10 | p. 200-220 | Jan./Abr. 2020 
Por isso, hoje o direito à privacidade é reconhecido a partir da conformação valorativa da inviolabilidade da pessoa humana, tornando-se possível à inclusão da vida particular como pretensão humana digna de valor jurídico que é capaz de proteger à pessoa natural ao estabelecer relações com outros seres humanos e com o mundo exterior:

"...seria muito restritivo limitar essa noção [de vida privada ou privacidade] a um "pequeno círculo" em que o indivíduo pode viver sua própria vida pessoal como bem entender e excluir dali em diante o mundo externo desse círculo. $\mathrm{O}$ respeito à vida privada deve também se comprometer em um dado grau ao direito de estabelecer e desenvolver relações com outros seres humanos." 8

Essa posição compreende que não é suficiente proteger a privacidade do indivíduo simplesmente de influências externas ou concedendo-lhe controle sobre certos tipos de interesses em determinados cenários ${ }^{9}$. Em vez disso, entende-se que a privacidade só pode ser alcançada quando se limitam os impactos adversos da relação jurídica, independentemente de elas estarem em círculos concêntricos (esfera secreta, íntima e privada) ou estarem relacionadas a ambientes públicos ou privados. Consequentemente, na visão contemporânea, forma-se uma proteção dual do direito à privacidade - que compreende decisão autônoma e os meios para consolidá-la - sendo estabelecida a noção de que "todos tem o direito ao respeito de suas vidas privadas e familiares, seu domicílio e sua correspondência” (CORTE EUROPEIA DE DIREITOS HUMANOS, 1974).

A partir dessas diferentes perspectivas teóricas e normativas do direito à privacidade emergem as seguintes questões: se a privacidade é qualificada de forma ampla, sua verificação e análise deve-se dar na aplicação de casos concretos? Como identificar, no âmbito dos direitos humanos, as situações jurídicas subjetivas que ela protege?

Tais inflexões motivaram a presente pesquisa que fornece uma revisão jurisprudencial do direito à privacidade no sistema regional europeu de direitos humanos. O estudo segue estruturado a partir de uma análise qualitativa realizada retrospectivamente no mês de dezembro de 2017. Procurou-se por jurisprudências publicadas na base de dados da Corte Europeia de Direitos Humanos, por meio dos descritores: privacidade; vida privada; vida familiar, domicílio, correspondência. Os dados foram reunidos para análise preliminar em janeiro de 2018. O estudo restringiu-se aos documentos: (1) relacionados à aplicação do direito à privacidade; (2) disponibilizados nos idiomas inglês, português ou espanhol. Foram excluídos os documentos não tinham a decisão integral disponível para consulta ou que estavam fora da temática aqui proposta. Os casos julgados foram reunidos para verificação qualitativa, sendo utilizado o método de análise de conteúdo (Bardin, 2011). Os resultados obtidos, podem ser observados no subitem abaixo.

\section{APLICAÇÃO DO DIREITO À PRIVACIDADE NO SISTEMA REGIONAL EUROPEU DE DIREITOS HUMANOS}

A partir da pesquisa jurisprudencial, foram localizados 83 casos julgados pela Corte Europeia de Direitos Humanos. Desse número total, 22 decisões dizem respeito à aplicação do termo vida privada; 07 (sete) versam sobre aplicação do termo vida familiar; 06 (seis) estão relacionadas ao termo domicílio; e 05 (cinco) tratam da proteção da correspondência. Foram

\footnotetext{
${ }^{8}$ CORTE EUROPEIA DE DIREITOS HUMANOS. Niemietz v. Germany, no. 13710/88. 1992. Livre Tradução: “... it would be too restrictive to limit the notion [of private life or privacy] to an "inner circle" in which the individual may live his own personal life as he chooses and to exclude therefrom entirely the outside world not encompassed within that circle. Respect for private life must also comprise to a certain degree the right to establish and develop relationships with other human beings".

${ }^{9}$ Tal posição foi introduzida no Brasil por Elimar Szaniawski. Ver: SZANIAWSKI, E. Direitos de Personalidade e sua tutela. Revista dos Tribunais, São Paulo. 2a Ed. 2005.p 355-356
}

Revista de Direito Brasileira | Florianólopis, SC | v. 25 | n. 10 | p. 200-220 | Jan./Abr. 2020 
excluídas da análise, 16 decisões que estavam fora do tema de pesquisa e 17 que estavam disponíveis na língua francesa. Os 40 casos que preencheram os critérios de inclusão foram reunidos para análise qualitativa, a fim de verificar quais as situações jurídicas subjetivas que estão protegidas na aplicação dos quatro termos previstos no artigo $8^{\circ}$ da Convenção para a Proteção dos Direitos Humanos e das Liberdades Fundamentais.

A análise dos casos demonstra que a Corte aplica o termo vida privada para proteger as situações jurídicas subjetivas relacionadas à identidade pessoal, à integridade, à imagem, aos dados pessoais e sensíveis do indivíduo. Já, o termo vida familiar abrange às situações jurídicas subjetivas associadas às relações formas e informais, às decisões reprodutivas e o controle do poder familiar. Para a Corte, o termo domicílio não se refere a um lugar em que a pessoa natural tem ânimo de permanecer, ao revés abrange lugares como em albergues, o estabelecimento comercial ou a casa do indivíduo. Em relação ao termo correspondência, a Corte protege as situações jurídicas subjetivas envolvendo manifestações escritas e orais, externadas por meio de cartas, e-mails, rede sociais e via telefone.

Por isso, verifica-se que o direito à privacidade no sistema regional de direitos humanos está protegido de forma abrangente, como um instrumento jurídico passível de aplicação, mas não de definição. Nesse sentido, o direito à privacidade visa, assim, promover uma posição de destaque da pessoa humana, não somente como um ser isolado (na lógica da exclusão), mas como um ser que dispõe de um viver privado - que é individual e familiar ao mesmo tempo - e de um viver social e político.

A existência de um caráter individual e relacional tornou preciso, ordenar as categorias jurídicas protegidas pelo direito à privacidade, com base no repertório de casos do sistema regional europeu de direitos humanos. Desta forma, no próximo subitem apresenta-se a aplicação do termo vida privada e sua proteção nas situações jurídicas subjetivas de conteúdo individual (2.1), para em seguimento, ser introduzida a aplicação dos termos vida familiar, correspondência e domicílio nas situações jurídicas subjetivas de caráter relacional (2.2).

\subsection{Vida privada e a proteção de situações jurídicas subjetivas de conteúdo individual:}

No sistema regional europeu, a aplicação do termo vida privada é verificado em nas situações jurídicas subjetivas associadas à identidade pessoal; à imagem; os dados pessoais; e os dados sensíveis do indivíduo. Nelas, a Corte aplica o direito à privacidade, a fim de garantir o livre desenvolvimento da personalidade do ser humano, possibilitando a sua distinção enquanto ser dotado de singularidade.

As situações jurídicas subjetivas, envolvendo à identidade pessoal do indivíduo, estão relacionadas a proteção da identidade de gênero, orientação sexual e vida sexual, integridade física e corporal, intervenções assistenciais de saúde ${ }^{10-11}$. (CORTE EUROPEIA DE DIREITOS HUMANOS, 1981, 2000, 2002c, 2007;).

\footnotetext{
${ }^{10}$ CORTE EUROPEIA DE DIREITOS HUMANOS. Caso Haas v. Switzerland, no. 31322/07. Suíça. 2011. Em especial, a maioria das intervenções assistências de saúde constitui uma interferência à integridade física e psicológica do indivíduo, porém o ato médico se justifica em prol da necessidade de proteger a saúde a os direitos dos seres humanos ou das comunidades. Por exemplo, nesse caso, a Corte afirma que a recusa do profissional de saúde em prescrever um medicamento para suicídio de um doente mental não viola o direito à privacidade, pois o direito à vida prevalece em face do direito à liberdade. É possível notar no caso Haas v. Switzerland, o qual aborda a recusa de medicamentos para ajudar no suicídio do requerente, que possui bipolaridade grave. A Corte é da opinião de que a restrição de acesso à substância é projetada para proteger a saúde pública e a segurança e para prevenir o crime.

${ }^{11}$ CORTE EUROPEIA DE DIREITOS HUMANOS. Caso Herczegfalvy v. Austria, no. 48/1991/300/371. Suíça. 1994. Reflexivamente, nesse caso a Corte sublinha que a administração forçada de alimentos se justifica quando há possibilidade prognóstico positivo para um paciente em tratamento médico.
}

Revista de Direito Brasileira | Florianólopis, SC | v. 25 | n. 10 | p. 200-220 | Jan./Abr. 2020 
Na visão da Corte, a identidade pessoal tem importância, na medida em que o indivíduo como unidade da vida social e jurídica, tem a necessidade de afirmar a sua própria personalidade, potencializando a sua singularidade:

“...a noção de" vida privada ", na acepção do artigo $8^{\circ}$ da Convenção é um conceito amplo que engloba, entre outros, o direito à autonomia pessoal e desenvolvimento pessoal. Trata-se de temas como a identificação de gênero, orientação sexual e vida sexual, integridade física e psicológica de uma pessoa, bem como as decisões, tanto para ter e não ter uma criança ou para se tornar pais biológicos ..."12

O termo vida privada aplicado às situações jurídicas subjetivas envolvendo à identidade de gênero e à orientação sexual do indivíduo, evidenciam como a privacidade garante o direito à autodeterminação das pessoas, devendo o Estado promover medidas efetivas que reconheçam o direito que cada pessoa tem de escolher autonomamente sua identidade pessoal.

Sobre essas questões, a Corte Europeia considera uma violação de direito à vida privada a recusa dos Estados em permitir que transexuais tenham acesso à cirurgia de transgenitalização, bem como a recusa para que esse grupo minoritário possa modificar seus documentos oficiais, a fim de compatibilizar seu prenome e gênero com suas informações pessoais (CORTE EUROPEIA DE DIREITOS HUMANOS, 2015a). ${ }^{13}$

No caso Dudgeon v. the United Kingdom, também envolvendo identidade pessoal, a Corte determinou a impossibilidade de criminalização da homossexualidade em sociedades democráticas:

... a conduta sexual privada, a qual é um elemento vital da esfera pessoal do indivíduo, não pode ser proibida meramente porque isso pode chocar ou ofender os outros. Em um aspecto tão intimo da vida privada, devem-se existir razões particularmente sérias antes que interferências sejam justificáveis. A corte ressaltou nesse contexto dois dos marcos de uma sociedade democrática: tolerância e a 'mente aberta'. ${ }^{14}$ (grifou-se)

Com efeito, é realmente possível identificar uma ampla proteção ao livre desenvolvimento da personalidade humana protegida pelo direito ao respeito à vida privada, fato que inclui à proteção da construção identitária dos indivíduos. Contudo, aos Estados-partes é garantida uma margem de apreciação para promoção e proteção do direito à identidade pessoal. Eles, podem limitar o exercício dessas liberdades em casos particulares, como por exemplo, na prática de sadomasoquismo (CORTE EUROPEIA DE DIREITOS HUMANOS, 1988, 2000).

A Corte Europeia vem decidindo que o reconhecimento da aplicação do artigo $8^{\circ}$ da Convenção gera o dever dos Estados-partes em não interferir no desenvolvimento da identidade

${ }^{12}$ CORTE EUROPEIA DE DIREITOS HUMANOS. A, $B$ and $C$ v. Ireland, no. 25579/05. Suíça. 2010. LT de: "The Court notes that the notion of "private life" within the meaning of Article 8 of the Convention is a broad concept which encompasses, inter alia, the right to personal autonomy and personal development. It concerns subjects such as gender identification, sexual orientation and sexual life, a person's physical and psychological integrity as well as decisions both to have and not to have a child or to become genetic parents..."

${ }^{13}$ CORTE EUROPEIA DE DIREITOS HUMANOS. Caso B v. France, no.13343/87, Suíça. 1995. No caso B v. France, a recorrente enquanto transexual alegou que a recusa do Estado em reconhecer a sua identidade sexual em documentos oficiais, como registro civil fez com que informações pessoais e sensíveis fossem acessadas por terceiros. A Corte declarou a violação do direito à privacidade da requerente nesse caso.

${ }^{14}$ CORTE EUROPEIA DE DIREITOS HUMANOS. Caso Dudgeon v. the United Kingdom. Suíça. 1981; LT de: “...that private sexual conduct, which is a vital element of an individual's personal sphere, cannot be prohibited merely because it may shock or offend others. In such an intimate aspect of private life, there must exist particularly serious reasons before interferences can be justified. The Court underlined in this context two of the hallmarks of a democratic society: tolerance and broadmindedness.” (grifou-se).

Revista de Direito Brasileira | Florianólopis, SC | v. 25 | n. 10 | p. 200-220 | Jan./Abr. 2020 
dos seres humanos. Entretanto, eles devem adotar medidas positivas para garantir que o seu desenvolvimento seja possível. ${ }^{15}$ Sobre esse ponto específico, ela decidiu que os Estados devem permitir que os indivíduos tenham acesso às informações que são vitais para a construção de sua identidade e personalidade, como dados oficiais sobre a sua infância (CORTE EUROPEIA DE DIREITOS HUMANOS, 1989).

Outra categoria associada à vida privada diz respeito às situações envolvendo a integridade humana. No âmbito do sistema regional europeu, a jurisprudência aponta que existe uma relação entre respeito à vida privada e à proteção à integridade pessoal do indivíduo que abrange as questões físicas, morais e psicológicas (CORTE EUROPEIA DE DIREITOS HUMANOS, 2010a).

A Corte Europeia de Direitos Humanos afirmou que embora a Convenção não estabeleça o direito à integridade pessoal em enunciado normativo específico, o direito à vida privada inclui situações jurídicas subjetivas envolvendo sua aplicação. $\mathrm{O}$ seu reconhecimento gera a obrigação positiva dos Estados-partes em garantir a seus cidadãos, de forma direta e imediata o respeito à sua autonomia pessoal e liberdade:

"Uma obrigação positiva de garantir aos seus cidadãos o direito ao respeito efetivo pela sua integridade física, psicológica e moral [que] pode implicar a adoção de medidas, incluindo o fornecimento de meios eficazes e acessíveis de proteção dos direitos ao respeito pela vida privada" 16

A conexão entre integridade e direito à privacidade, refere-se à autonomia e à liberdade dos indivíduos sobre seu próprio corpo, manifestando-se na proteção contra intromissões não autorizadas em seu espaço íntimo. Essa proteção se reflete no direito de determinar quem acessa, toca ou poderá coletar materiais genéticos e biológicos do indivíduo, dentre outras situações. (CORTE EUROPEIA DE DIREITOS HUMANOS, 2007a)

No caso Gillan and Quinton v. the United Kingdom, a Corte Europeia decidiu que as abordagens policiais de revista, quando realizadas sem suspeitas razoáveis contra o individuo violam o direito à privacidade (CORTE EUROPEIA DE DIREITOS HUMANOS, 2010a). Igualmente no caso $A, B$ and $C$ v. Ireland, a Corte sublinhou que as restrições legais impostas ao aborto na Irlanda interferiram na parte mais íntima da vida privada das partes, incluindo consequências à integridade física de cada gestante, em vista da falta de liberdade. (CORTE EUROPEIA DE DIREITOS HUMANOS, 2010b)

A proteção da integridade não se limita ao espectro físico humano. No caso Haas $v$. Switzerland, a proteção da integridade psicológica da pessoa humana foi destacada. Nele, a Corte avaliou se o fornecimento de medicamentos para fins de suicídio seria possível, com base na aplicação do termo vida privada. Para isso, apresentou duas alternativas: (i) considerada a permissão de fornecimento de medicamento dentro deste escopo, teria o solicitante o direito de dispor sobre a sua integridade física e psicológica; ou (ii) não considerada a solicitação dentro do escopo do artigo $8^{\circ}$ da Convenção, pois existe um limite na atuação do direito a privacidade, com

\footnotetext{
${ }^{15}$ CORTE EUROPEIA DE DIREITOS HUMANOS. Caso Laskey, Jaggard \& Brown v. the United Kingdom, nos.21627/93, 21826/93 e 21974/93. Suíça. 1997. Nesse caso, a Corte decidiu que a identidade sexual é parte da vida privada de um indivíduo. O respeito à vida privada do artigo $8^{\circ}$, garante assim, uma esfera dentro da qual uma pessoa pode estabelecer relações de diferentes tipos, incluindo as sexuais. Considera-se que a identidade de uma pessoa é amplamente protegida, inclusive no seu caráter mais íntimo, como a identidade sexual. No caso Laskey, Jaggard \& Brown v. the United Kingdom é possível perceber claramente a decisão da Corte abrangendo a identidade sexual, seguindo com a justificativa que o respeito pela vida privada também abrange a proteção da moral.

${ }^{16}$ CORTE EUROPEIA DE DIREITOS HUMANOS. Caso McGinley and Egan v. the United Kingdom, no. $21825 / 93$ e 23414/94; Suíça. 1998. LT de: "a positive obligation to secure to their citizens the right to effective respect for their physical, psychological and moral integrity [which] may involve the adoption of measures including the provision of an effective and accessible means of protecting the rights to respect for private life".
}

Revista de Direito Brasileira | Florianólopis, SC | v. 25 | n. 10 | p. 200-220 | Jan./Abr. 2020 
base na segurança da integridade do indivíduo. A Corte adotou a segunda hipótese, mesmo em um país em que o suicídio assistido é permitido. Decidiu, assim, pela recusa do fornecimento de medicamentos e sublinhou que o caso não dizia respeito à liberdade de morrer, mas sobre a abrangência da aplicação do direito à privacidade (CORTE EUROPEIA DE DIREITOS HUMANOS, 2011a).

A Corte define integridade, como aquela que protege os aspectos humanos físicos, psíquicos e morais, constituindo, assim, uma unidade, representada pela personalidade. Segundo a Corte, a integridade se traduz em casos relacionados com o direito à saúde (CORTE EUROPEIA DE DIREITOS HUMANOS, 1981, 2011a).

No sistema regional europeu, a saúde do indivíduo, não se reduz a um perfil estático e individual, mas se associa com o livre desenvolvimento da pessoa humana. Essa afirmação pode ser exemplificada no julgamento do caso Dubská And Krejzová v. The Czech Republic (CORTE EUROPEIA DE DIREITOS HUMANOS, 2014). Nesse caso, a Corte avaliou se o Estado deveria promover políticas públicas de acesso a partos domiciliares, em vista da percepção de privacidade de algumas gestantes. A resposta incluiu, nas palavras da Corte, uma consideração sobre o respeito às decisões privadas:

"... A Corte considera que o parto é um aspecto particularmente íntimo da vida privada de uma mãe. Ele engloba questões de integridade física e psicológica, a intervenção médica, a saúde reprodutiva e a proteção da informação relacionada à saúde. As decisões a respeito das circunstâncias do parto, incluindo a escolha do local de nascimento, portanto, se inserem no âmbito da vida privada da mãe para os efeitos do artigo $8^{\prime 17}$

Baseando-se na jurisprudência, a Corte considerou que o parto é um aspecto particularmente íntimo da vida privada feminina, no sentido de que esse ato humano engloba questões de integridade física e psicológica, intervenção médica, saúde reprodutiva e proteção de informações relacionadas com a saúde. Logo, as decisões a respeito das circunstâncias do parto, incluindo a escolha do local de nascimento são abrangidos pelo âmbito da vida privada da gestante para os efeitos do artigo $8^{\circ}$ da Convenção Europeia. Contudo, assinala a Corte que " $a$ Convenção, uma vez que as obrigações de respeitar as circunstâncias individuais de dar à luz e à vida privada da mãe teve que ser distinguida da obrigação de estabelecer um modelo de assistência para permitir um parto em casa.",18

Além disso, identificou-se que na aplicação do termo vida privada há proteção da imagem, direito que assegura ao indivíduo o poder de controlar como a sua representação física - expressada de forma plástica, analógica ou exata - por meio de pintura, fotografias, escultura, vídeos, e linguagem circula na sociedade. Nessa dimensão, a imagem enquanto forma material que contém características físicas ou morais de um indivíduo é projetada perante terceiros, de forma que gera repercussões de privacidade à pessoa ou à comunidade. Tais situações jurídicas subjetivas são assinaladas pela Corte Europeia:

\footnotetext{
${ }^{17}$ CORTE EUROPEIA DE DIREITOS HUMANOS. Dubská and Krejzová v. the Czech Republic. Suíça, 2014. LT de: “...the Court considers that giving birth is a particularly intimate aspect of a mother's private life. It encompasses issues of physical and psychological integrity, medical intervention, reproductive health and the protection of healthrelated information. Decisions regarding the circumstances of giving birth, including the choice of the place of birth, therefore fall within the scope of the mother's private life for the purposes of Article 8".

${ }^{18}$ CORTE EUROPEIA DE DIREITOS HUMANOS. Dubská and Krejzová v. the Czech Republic. Suíça, 2014. LT de: "the Convention, since the obligations to respect the individual circumstances of giving birth and the private life of the mother had to be distinguished from the obligation to establish a framework to allow assistance at a home birth.".
} 
“... A Corte esclareceu que a imagem de uma pessoa constitui um dos principais atributos de sua personalidade, pois revela características únicas da pessoa e distingue a pessoa de seus pares. $\mathrm{O}$ direito à proteção da imagem da pessoa é, portanto, um dos componentes essenciais do desenvolvimento pessoal. Ele pressupõe, principalmente, o direito do indivíduo de controlar o uso dessa imagem, incluindo o direito de recusar a publicação dos mesmos." ${ }^{19}$

A Corte, ao incluir a imagem como um desdobramento do direito à privacidade, esclarece que a imagem de uma pessoa constitui um dos principais atributos de sua personalidade, pois revela características únicas da mesma e distingue-a de seus pares. O direito à proteção da imagem de um indivíduo é, portanto, um dos componentes essenciais do desenvolvimento da personalidade humana. Com esse entendimento, a Corte reitera o conceito amplo do direito à privacidade e inclui no seu espectro de aplicação, aspectos ligados à identidade pessoal, como nome, imagem, integridade física e moral de uma pessoa. (CORTE EUROPEIA DE DIREITOS HUMANOS, 2009a; 2012a)

A semântica da palavra imagem pode limitá-la ao aspecto visual ou físico do ser humano. Contudo, a acepção jurídica da palavra, como sublinha a Corte Europeia, incide em qualquer expressão formal e sensível que seja suficiente para fazer assimilar a imagem de um indivíduo. (CORTE EUROPEIA DE DIREITOS HUMANOS, 1985)

Em virtude dessa posição jurídica, no caso Nada v. Switzerland, a Corte ressaltou que a associação de um indivíduo a uma imagem que lhe cause danos, viola o direito à privacidade. Nesse caso o nome do Sr. Nada, pelo fato de ser mulçumano, foi incluído na Portaria Federal Taliban, pelas autoridades estatais Suíças, sendo sua imagem associada ao grupo Al-Qaeda. Esse fato acarretou a proibição de locomoção do Sr. Nada dentro da Suíça, gerando prejuízos profissionais e familiares. Sua imagem cultural e física foi utilizada como forma de legitimar um estigma social, fato que gerou um dano e uma violação à sua privacidade. (CORTE EUROPEIA DE DIREITOS HUMANOS, 2012b)

Logo, dentre as finalidades do artigo $8^{\circ}$ da Convenção Europeia está à proteção do uso e acesso da imagem dos indivíduos, sendo, preservada, em alguns casos, inclusive à privacidade de pessoas públicas (CORTE EUROPEIA DE DIREITOS HUMANOS, 2002b). Essa garantia gera a obrigação negativa dos Estados em não interferir no desenvolvimento e na disposição da própria imagem do indivíduo.

A próxima categoria envolvendo aplicação do termo vida privada, visa proteger situações jurídicas subjetivas em que há trânsito de dados pessoais e sensíveis. As decisões envolvendo a proteção desses dados estão associadas a busca de uma justificativa adequada para que os Estadospartes e entes privados possam coletar, armazenar e acessar informações pessoais e sensíveis sobre um determinado indivíduo.

Essas medidas geralmente se relacionam com três grupos específicos: as informações coletadas e armazenadas por instituições estatais de segurança nacional para fins de prevenção e detecção de crimes; arquivos contendo informações pessoais e sensíveis mantidos pelos serviços de segurança em prol da promoção da segurança nacional; e os dados pessoais e sensíveis gerados pelo indivíduo ou por terceiros com fins lícitos que são armazenados por entes públicos ou particulares.

A Corte Europeia entende que dados pessoais podem ser armazenados em bancos de dados estatais para fins de persecução criminal. Isto é, as autoridades estatais poderão coletar e armazenar dados pessoais em seus registros e investigações referentes ao indivíduo suspeito, em vista da

\footnotetext{
${ }^{19}$ CORTE EUROPEIA DE DIREITOS HUMANOS. Caso Von Hannover v. Germany, no. 59320/00. Suíça. 2004-VI; LT de: “...the Court has stated that a person's image constitutes one of the chief attributes of his or her personality, as it reveals the person's unique characteristics and distinguishes the person from his or her peers. The right to the protection of one's image is thus one of the essential components of personal development. It mainly presupposes the individual's right to control the use of that image, including the right to refuse publication thereof."
}

Revista de Direito Brasileira | Florianólopis, SC | v. 25 | n. 10 | p. 200-220 | Jan./Abr. 2020 
segurança nacional, sem que esse ato constitua uma violação do direito à privacidade (CORTE EUROPEIA DE DIREITOS HUMANOS, 1994a). Por exemplo, na decisão do caso Uzun $v$. Germany, o Tribunal Europeu afirmou que monitoramento via GPS de suspeitos de terrorismo não constituí violação do direito à privacidade. (CORTE EUROPEIA DE DIREITOS HUMANOS, 2010c)

Contudo, a ação de prevenção e investigação deve ser realizada quando existe, efetivamente, um processo judicial, uma suspeita razoável ou uma investigação contra organizações criminosas e terroristas, pois o interesse público em prol da manutenção da ordem e segurança não é ilimitado (CORTE EUROPEIA DE DIREITOS HUMANOS, 1987b).

Por exemplo, no caso $S$. and Marper v. the United Kingdom, a Corte considerou que o armazenamento e manutenção de dados sensíveis (material genético humano) para fins de persecução criminal têm um prazo limite razoável, de forma que o registro do dado sensível deve ser mantido até a data de absolvição ou condenação do indivíduo, sob pena de violação do direito à privacidade (CORTE EUROPEIA DE DIREITOS HUMANOS, 2008). Nesse caso, as partes solicitantes entraram com a queixa na Corte Europeia, com base nas disposições dos artigos $8^{\circ} \mathrm{e}$ 14 da Convenção, alegando que o Reino Unido mantinha armazenado as suas impressões digitais, amostras celulares e de DNA, mesmo após a absolvição em um processo criminal. Com base nas provas constantes no processo a Corte assinalou que: "Dada a natureza e a quantidade de informações confidenciais contidas em amostras celulares, a sua retenção por si só deve ser considerada como uma interferência com o direito ao respeito à vida privada das pessoas envolvidas "20 (CORTE EUROPEIA DE DIREITOS HUMANOS, 2008)

Em outro caso envolvendo a coleta e o armazenamento de dados sensíveis, denominado Van der Velden, a Corte destacou que a posterior utilização de material biológico ou genético é suficiente para configurar uma interferência na vida privada do indivíduo que coletou a amostra. Esse fato gera a obrigatoriedade dos Estados-partes em proteger o uso e acesso destas informações sensíveis. (CORTE EUROPEIA DE DIREITOS HUMANOS, 2006)

No que compete ao uso de dados sensíveis, a Corte observa que a falta de lei estatal sobre a coleta e armazenamento de tecidos e partes do corpo humano sem o consentimento da família de pessoa falecida viola o respeito ao direito à privacidade. Nesse caso, a requerente queixou-se, nos termos do artigo $8 .^{\circ}$ da Convenção, que a coleta do material biológico de seu marido tinha sido realizada sem o consentimento prévio dela ou do de cujos. A Corte reconheceu que dados sensíveis fazem parte do espectro de aplicação do artigo $8^{\circ}$ da Convenção e que a ausência de consentimento informado para coleta de material biológico violou a dignidade, identidade e integridade do falecido, expressadas no direito à privacidade. (CORTE EUROPEIA DE DIREITOS HUMANOS, 2015b)

Em relação ao acesso de dados pessoais, a Corte Europeia entende que os indivíduos devem ter acesso a informações que são vitais para a construção de sua identidade e personalidade, como dados sobre a sua infância (CORTE EUROPEIA DE DIREITOS HUMANOS, 1989). Especialmente, nesse caso, o requerente foi mantido sob os cuidados do Estado até completar a maioridade civil, e após isso solicitou o acesso aos seus dados pessoais, como registros sobre sua infância e histórico de desenvolvimento. O Tribunal decidiu que nos casos em que há interesse legítimo deve-se fazer um juízo de proporcionalidade entre o interesse público e o interesse privado de forma que uma autoridade independente, finalmente, decide se o acesso deve ser concedido nos

\footnotetext{
${ }^{20}$ CORTE EUROPEIA DE DIREITOS HUMANOS. Caso S. and Marper $v$. the United Kingdom, $30562 / 04$ and 30566/04. Suíça, 2008; LT de: "Given the nature and the amount of sensitive information contained in cellular samples, their retention per se must be regarded as interfering with the right to respect for the private lives of the individuals concerned."
} 
casos em que um contribuinte não responde ou retém consentimento". ${ }^{21}$ Confirmando a posição acima, em outro caso, a Corte assinalou que os dados de saúde (dados sensíveis) são dados confidenciais, porém devem ser acessados pelo indivíduo que consentiu para o seu uso, podendo inclusive retirar fotocópias do seu prontuário médico (CORTE EUROPEIA DE DIREITOS HUMANOS, 2007b).

A comunicação de dados pessoais e sensíveis também foi objeto de apreciação e aplicação. Particularmente, sobre dados sensíveis a Corte confirma ser vital: "nos sistemas jurídicos das partes contratantes da Convenção a confidencialidade dos dados de saúde devem ser respeitados ". ${ }^{22}$ Consequentemente, a existência de mecanismos de proteção à confidencialidade de dados de saúde se relaciona não só com o direito do indivíduo de proteção à privacidade, mas com a confiança dele na relação médico-paciente e no sistema de saúde em geral. Daí porque, nesse caso, a Corte ressaltou que o consentimento do paciente é pressuposto para o ato de comunicação:

[I] n Dada a natureza altamente íntima e sensível das informações referentes ao status do HIV de uma pessoa, qualquer medidas estatais de comunicação persuasiva ou divulgação de tais informações sem o consentimento do paciente chamado para a análise mais cuidadosa por parte da Corte, assim como as garantias destinadas a garantir uma proteção eficaz. ${ }^{23}$

Curiosamente, em outro caso envolvendo o dever de confidencialidade, a Corte determinou a legalidade de uma norma regional que imputa a obrigação aos advogados em denunciar suspeitos por lavagem de dinheiro, com base nas informações pessoais reveladas por seus clientes durante a prestação de assistência judiciária ou com base em correspondências (CORTE EUROPEIA DE DIREITOS HUMANOS, 2013). Nesse caso, o requerente apresentou uma queixa à Corte, alegando que a União Europeia havia adotado três diretivas destinadas a prevenir a utilização do sistema financeiro para lavagem de dinheiro. Dentre os dispositivos das diretivas existia a obrigação dos advogados de notificarem suspeitas por lavagem de dinheiro. Isso implicou na revelação de informações confidenciais recebidas de forma privilegiada pelo profissional que prestava assistência judiciária. Em face disso, a Corte assinalou que a intenção de combater a lavagem de dinheiro e criminalidade associada consiste em um dos objetivos legítimos previstos no segundo parágrafo do artigo $8^{\circ}$ da Convenção, ou seja, a prevenção de desordem e crime. (CORTE EUROPEIA DE DIREITOS HUMANOS, 2013)

Visto dessa forma, a imputação de responsabilidade aos advogados pelas diretivas europeias não foi considerada uma ingerência desproporcional, na medida em que a Corte considerou que um dos objetivos legítimos e de importância particular para Europa é a construção de uma sociedade democrática livre de corrupção e lavagem de dinheiro. (CORTE EUROPEIA DE DIREITOS HUMANOS, 2013)

A consequência da aplicação do conteúdo do artigo $8^{\circ}$ da Convenção Europeia, relativo ao direito à privacidade no uso e acesso de dados pessoais e sensíveis se liga às situações jurídicas subjetivas envolvendo o direito de identidade e de integridade física, moral e psicológica, não sendo uma dimensão isolada, mas uma categoria que se comunica com demais dimensões do ser humano.

\footnotetext{
${ }^{21}$ CORTE EUROPEIA DE DIREITOS HUMANOS. Caso Gaskin v. the United Kingdom, no. 104598. Suíça. 1989; LT de: it provides that an independent authority finally decides whether access has to be granted in cases where a contributor fails to answer or withholds consent".

${ }^{22}$ CORTE EUROPEIA DE DIREITOS HUMANOS. Caso Z v. Finland, no. 5868/02. Suíça. 1997; LT de: “it is a vital principle in the legal systems of the Contracting Parties to the Convention that the confidentiality of health data be respected".

${ }^{23}$ CORTE EUROPEIA DE DIREITOS HUMANOS. Caso Z v. Finland, no. 5868/02. Suíça. 1997; LT de: [i]n view of the highly intimate and sensitive nature of information concerning a person's HIV status, any State measures compelling communication or disclosure of such information without the consent of the patient call for the most careful scrutiny on the part of the Court, as do the safeguards designed to secure an effective protection.
}

Revista de Direito Brasileira | Florianólopis, SC | v. 25 | n. 10 | p. 200-220 | Jan./Abr. 2020 
No sistema regional europeu, o termo vida privada está associado a casos envolvendo diferentes situações jurídicas subjetivas - dados pessoais e sensíveis, identidade pessoal e imagem -, mas todas com um fio condutor: o livre desenvolvimento da personalidade que possui um caráter marcadamente individual, porém às vezes poderá assumir uma conotação relacional. Nessa permanente dualidade, a Corte Europeia reconhece que os seres humanos são eminentemente sociais, de forma que encontram no viver - vida de relações - a dimensão de sua própria existência. Essa noção faz com que os indivíduos saiam da zona singular, de um espaço privado, para uma zona relacional, marcada por um espaço compartilhado. $\mathrm{O}$ entendimento da perspectiva relacional do direito à privacidade faz parte do escopo do próximo subitem.

\subsection{Vida familiar, a correspondência, o domicílio e a proteção de situações jurídicas subjetivas de conteúdo relacional.}

No sistema regional europeu, a amplitude relacional abrange situações jurídicas subjetivas associadas a capacidade e a liberdade do indivíduo estabelecer e determinar suas próprias relações pessoais com base nas suas convicções de privacidade. Nessa perspectiva, são destacados pela Corte os âmbitos de proteção concernentes aos termos: vida familiar, correspondência e domicílio.

No que toca à proteção da vida familiar, a Corte Europeia observa que disposto no artigo $8^{\circ}$ da Convenção pressupõe a existência real da prática de laços pessoais, sejam eles biológicos ou não (CORTE EUROPEIA DE DIREITOS HUMANOS, 1974). No sistema regional europeu, a noção de família não se limita apenas às relações baseadas em casamentos, podendo abranger outros vínculos familiares que não sejam eventuais, uma vez que a vida familiar é protegida e seu reconhecimento gera a repercussão em vários casos concretos em matéria de proteção à privacidade quando relacionada aos membros familiares. (CORTE EUROPEIA DE DIREITOS HUMANOS, 1994b, 1997b)

A proteção do direito à privacidade familiar, também, compreende um conteúdo amplo e elástico, variando conforme tempo e mérito das relações afetivas. A Corte aplica esse termo em situações jurídicas subjetivas envolvendo: acesso as técnicas de reprodução humana assistida (CORTE EUROPEIA DE DIREITOS HUMANOS, 2007c), reconhecimento de filhos advindos de maternidade substitutiva (CORTE EUROPEIA DE DIREITOS HUMANOS, 2011b); recusa em apresentar identidade feminina ao marido após cirurgia transgenitalização (CORTE EUROPEIA DE DIREITOS HUMANOS, 2007d).

No que toca o significado do termo correspondência, claramente a Corte inclui objetos físicos que são remetidos via postal. Porém, a ela tem entendido que o significado literal deste termo deve ser estendido em vista da evolução das tecnologias de comunicação, incluindo, assim, a comunicação via telefone, e-mails, redes sociais e aplicativos, no sentido de garantir que exista um nível adequado de proteção para as diferentes "correspondências" que poderá variar conforme o tempo e a evolução dos métodos de comunicação. (CORTE EUROPEIA DE DIREITOS HUMANOS, 1993)

Em relação ao termo domicílio, a Corte afirma que no geral ele significa o lugar onde se reside ou onde se está situado, por isso a interpretação de domicílio foi estendida a albergues e alojamentos temporários no caso Gillow v. the United Kingdom (CORTE EUROPEIA DE DIREITOS HUMANOS, 1986). Da mesma forma, a Corte entende que a noção de domicílio inclui o estabelecimento comercial (CORTE EUROPEIA DE DIREITOS HUMANOS, 1992). O reconhecimento dessa extensão da proteção do direito à privacidade gera a obrigação das autoridades estatais e demais particulares de não violarem a casa dos indivíduos ou estabelecimentos comerciais, bem como gera o dever dos Estados-partes de garantir, por meio de safeguards, que esse direito tenha efetividade. As safeguards neste ponto se manifestam, entre outras hipóteses, por meio da proibição de acesso a determinados ambientes sem autorização legal, 
de buscas e apreensões abusivas e escuta ambiental não autorizada. (CORTE EUROPEIA DE DIREITOS HUMANOS, 1997a)

$\mathrm{O}$ entendimento de cada termo demonstra que o direito à vida privada segue aplicado em casos envolvendo o livre desenvolvimento da personalidade do indivíduo - conforme suas percepções pessoais de privacidade. Já os termos vida familiar, correspondência e domicílio o direito à privacidade relacional se conectam aos casos envolvendo limites de intervenção dos Estados, particulares e terceiros na vida de um indivíduo que compartilha informações, espaços de habitação e faz parte de um grupo social.

No sistema regional europeu, o repertório de casos julgados auxilia no entendimento de como se dá a concretização do direito à privacidade. Tal análise é possível em vista do número expressivo de decisões da Corte Europeia de Direitos Humanos, fato que não se verificou com o mesmo número de ocorrência na Corte Interamericana de Direitos Humanos ${ }^{24}$. Apesar disso, no sistema regional interamericano é dada interpretação ampla ao direito à privacidade, sendo ele caracterizado como aquele que não permite invasões ou agressões abusivas ou arbitrárias por parte de terceiros ou da autoridade pública na vida privada do indivíduo ${ }^{25}{ }^{26}{ }_{-}^{27}$. Essa posição obriga os

\footnotetext{
${ }^{24}$ Em relação ao número de decisões da Corte Interamericana de Direitos Humanos envolvendo a proteção ao direito à privacidade, foram localizados sete casos, sendo que somente uma queixa estava relacionada diretamente ao direito à privacidade.

${ }^{25}$ A Corte Interamericana de Direitos Humanos declarou a Colômbia responsável pelo massacre em Antioquia, cometido por paramilitares da Autodefesas Unidas da Colômbia. A AUC invadiu povoados de La Granja e El Aro, localizado no município Ituango - Antioquia. Na primeira investida, houve morte de 19 pessoas, desestruturação das comunidades e impedimento do crescimento econômico, social e afetivo das famílias. A denúncia à Corte foi dada através da Convenção Americana, visando o desrespeito ao direito à vida, das crianças, da liberdade e integridade pessoal, à propriedade privada, detenção de pessoas sem justificativa e obrigação de trabalhos forçados. Ver em: MAZZUOLI, Valerio de Oliveira, "Tratados internacionais dos Direitos Humanos, (p 956 a 982), in Curso de Direito Internacional Público, $5^{\mathrm{a}}$. edição, revista, atualizada e ampliada; Dinah Shelton, Regional protection of human rights, cit., pp. 68-85.

${ }^{26}$ Além disso, a Corte interpretou de forma ampla o artigo 7 da Convenção Americana ao afirmar que este direito inclui um conceito de liberdade em um sentido extenso como a capacidade de fazer e não fazer tudo o que esteja licitamente permitido. Em outras palavras, constitui o direito de toda pessoa de organizar, de acordo com a lei, sua vida individual e social em conformidade com suas próprias opções e convicções. Ver: CORTE INTERAMERICANA DE DIREITOS HUMANOS. Caso Chaparro Álvarez e Lapo Íñiguez. Vs. Equador. Costa Rica, 2007.

${ }^{27}$ Entendeu que a liberdade é um direito humano básico, próprio dos atributos da pessoa, que se projeta em toda a Convenção Americana e garante a possibilidade de todo ser humano de se autodeterminar e escolher livremente as opções e circunstâncias que dão sentido à sua existência, em conformidade com suas próprias opções e convicções de privacidade. Ver: CORTE INTERAMERICANA DE DIREITOS HUMANOS. Caso Atala Riffo e Crianças Vs. Chile. Costa Rica, 2012.
} 
Estados-membros a formularem medidas para garantir à liberdade reprodutiva ${ }^{28}{ }_{-}^{29}{ }_{-}^{30}$, à integridade física e psicológica do indivíduo, na medida em que a privacidade é uma condição indispensável para o livre desenvolvimento da personalidade humana. ${ }^{31}{ }^{32}$

\begin{abstract}
${ }^{28}$ María Claudia García Iruretagoyena Casinelli e Marcelo Ariel Gelman Schubaroff, ambos argentinos, foram detidos junto com familiares e amigos em 1976 em Buenos Aires, por militares uruguaios e argentinos em uma operação chamada "Operação Condor", marco de práticas sistemáticas de detenções, torturas, execuções

extrajudiciais e desaparecimentos forçados na ditadura cívica-militar. María, no momento de sua privação de liberdade, estava grávida de 7 meses e foi removida clandestinamente para o Uruguai, onde deu à luz a uma menina. A criança foi entregue a autoridades uruguaias e, desde então, María se encontra desaparecida. Em 2000, a criança obteve contato com o avô paterno e em 2005 adotou o sobrenome dos pais biológicos. A Corte Interamericana, por fim, declarou o Estado uruguaio responsável pelo desaparecimento de María Claudia e de violar uma série de direitos, como, por exemplo, reconhecimento de personalidade jurídica, à vida privada, à integridade pessoal, ao nome, à nacionalidade e diversos outros. Consultar em: CORTE INTERAMERICANA DE DIREITOS HUMANOS. Caso Gelman Vs. Uruguai. Costa Rica, 2011.

${ }^{29}$ CORTE INTERAMERICANA DE DIREITOS HUMANOS. Caso Artavia Murillo vs Costa Rica, 2012. Neste caso, a Corte reconheceu que o direito à vida privada se relaciona com: i) a autonomia reprodutiva, e ii) o acesso a serviços de saúde reprodutiva, o que envolve o direito de ter acesso à tecnologia médica necessária para exercer esse direito. $\mathrm{O}$ direito à autonomia reprodutiva está reconhecido também no artigo 16 (e) da Convenção sobre a Eliminação de todas as Formas de Discriminação contra a Mulher, segundo o qual as mulheres gozam do direito "de decidir livre e responsavelmente sobre o número de filhos e sobre o intervalo entre os nascimentos e a ter acesso à informação, à educação e aos meios que lhes permitam exercer estes direitos". Este direito é violado quando se obstaculizam os meios através dos quais uma mulher pode exercer o direito a controlar sua fecundidade. Logo, a Corte ampliou o escopo de de proteção à vida privada para incluir o respeito às decisões de se converter em pai ou mãe, incluindo a decisão do casal de se converter em pais genéticos. Sobre os efeitos dessa decisão no Brasil, consultar: STOLL DE MORAIS, L. et al. DIREITO DE ACESSO E USO DA TÉCNICA DE FERTILIZAÇÃO IN VITRO NA PERSPECTIVA DA CORTE INTERAMERICANA DE DIREITOS HUMANOS. Revista de Direito Brasileira, v.
\end{abstract} 17, n. 7, p. 275, 26 set. 2017.

${ }^{30}$ Em sentido similar: CORTE EUROPEIA DE DIREITOS HUMANOS. Caso Evans Vs. Reino Unido, (n 6339/05). Suíça. 2007, pars. 71 e 72; em que a Corte afirmou que "private life"” [...] incorporates the right to respect for both the decisions to become and not to become a parent", LT: vida privada engloba o direito de respeitar ambasa as decisões de se tornar ou não pai/mãe; e sublinhou quanto à regulamentação da prática de Fecundação in vitro (FIV) que "the right to respect for the decision to become a parent in the genetic sense, also falls within the scope of Article 8", LT: o direito de respeitar a decisão de se tornar pai/mãe no sentido biológico, também está incluído no escopo do Artigo $8^{\circ}$.

${ }^{31}$ CORTE INTERAMERICANA DE DIREITOS HUMANOS. Caso rosendo cantú y otra vs. méxico. Costa Rica, 2010. Nesse caso, a Corte Interamericana de Direitos Humanos declarou que o Estado mexicano é responsável pela violação dos direitos à integridade pessoal, à dignidade, à privacidade, aos direitos das crianças, às garantias judiciais e proteções judiciais. Com base nos fatos, foi comprovado que em 2002, a requerente indígena Rosendo Cantú foi cercada perto de seu domicílio por oito militares, entre esses um a interrogando e outro apontando uma arma à ela, o qual a golpeou, fazendo-a perder a consciência por um tempo curto. Quando Cantú retomou consciência, foi agredida fisicamente e violentada sexualmente, igualmente os policiais a ameaçaram de morte. Perante as circunstâncias, a Corte Interamericana reiterou que a violência contra a mulher não constitui somente uma violação de direitos humanos, como também uma ofensa à dignidade da pessoa humana que transcende todos os setores da sociedade $\mathrm{e}$ afeta negativamente suas próprias bases. No presente caso, a violação sexual tornou vulnerável os valores e aspectos essenciais da privacidade e da integridade pessoal, constituindo, inclusive, um ato de tortura.

${ }^{32}$ CORTE INTERAMERICANA DE DIREITOS HUMANOS. Caso Ximenes Lopes v. Brasil. 2006. primeira condenação do país pela Corte Interamericana. Diante das circunstâncias dos fatos, Damião Ximenes Lopes era portador de deficiência mental e, em 4 de outubro de 1999, veio à óbito na instituição psiquiátrica denominada Casa de Repouso Guararapes, centro de saúde vinculado ao Sistema Único de Saúde, em Sobral, CE. A necropsia revelou que, dias após sua internação, o paciente foi sujeito à contenção física e tortura e privado de manifestar seu direito autodeterminação informativa. Apesar dos sinais de maus-tratos, o atestado tinha que a causa da morte foi indeterminada. A Corte decidiu, entre outros pontos, que o Estado deve garantir um processo interno destinado a sancionar os responsáveis pelos maus-tratos; o Estado deve reparar a família, desenvolvendo um programa de capacitação para profissionais da área da saúde, conforme os padrões internacionais. 


\section{CONSIDERAÇÕES FINAIS}

Os resultados da presente pesquisa indicam que no sistema regional europeu de direitos humanos o direito à privacidade é protegido de forma ampla, não sendo possível defini-lo. O Corte Europeia compreende que o artigo $8^{\circ}$ da Convenção para a Proteção dos Direitos Humanos, em um sentido lato, protege o desenvolvimento individual do ser humano. Porém, essa garantia não elimina o reconhecimento da dimensão relacional da pessoa natural, principalmente porque a Corte considera que o individuo estabelece e desenvolve relações com outros seres humanos e com o mundo exterior, devendo ser tutelada sua vida privada, familiar, seu domicílio e sua correspondência.

O fator positivo dessa conclusão é que o conteúdo do direito à privacidade será definido a partir da análise dos fatos e das alegações propostas pelas partes, em casos concretos. Isso garante que a privacidade não receba uma definição e sua aplicação seja feita por meio da operabilidade. Contudo, isso pode gerar pouco entendimento sobre como protegê-la e aplicá-la. Por esse motivo, verificou-se a necessidade de categorizar as situações jurídicas subjetivas que fazem parte do escopo de aplicação do artigo $8^{\circ}$ da Convenção para a Proteção dos Direitos Humanos. A figura abaixo sintetiza os resultados obtidos através da análise de conteúdo dos casos jurisprudenciais apreciados pela Corte Europeia (figura 1).

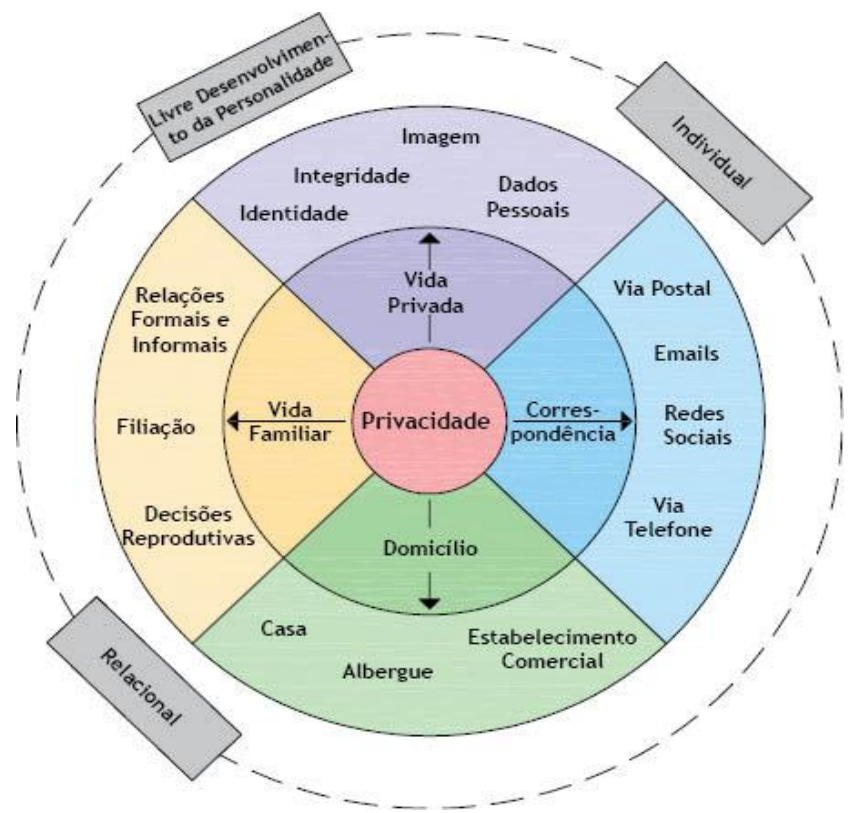

Figura. 1 - Direito à privacidade no Sistema Regional Europeu de Direitos Humanos (Fonte do autor)

As diferentes situações jurídicas subjetivas acima esquematizadas não excluem outras existentes, mas traduzem que a pessoa humana é um ser vivo que dispõe de um viver social, político e institucional, fato que modifica a noção clássica de que o direito à privacidade visa, apenas, proteger o aspecto negativo do indivíduo: o direito de ser deixado só ou de não ter a própria vida devassada ou publicizada. Hoje, o direito à privacidade representa um instrumento jurídico que permite à pessoa humana se relacionar com outras a partir de decisões responsáveis.

Os resultados da pesquisa indicam que o tratamento conferido à privacidade pelo sistema regional europeu de direito humanos consolida o direito à autonomia dos indivíduos, marcando assim, o desenvolvimento da personalidade dos seres humanos, do ponto de vista individual e relacional. Nesse sentido, o entendimento sublinhado pela Corte Europeia, nos casos concretos, revela que o caráter individual do direito à privacidade inclui uma série de fatores ligados à 
autonomia privada da vontade, como, por exemplo, a capacidade da pessoa natural para desenvolver a própria personalidade e aspirações pessoais, como, a identidade, integridade imagem e dados pessoais. Já o caráter relacional está associado à capacidade e à liberdade do individuo em determinar e estabelecer suas relações sociais através de relações formais, informais ou por meio da comunicação.

Portanto, no sistema regional europeu, a privacidade recebe uma dupla perspectiva: garante a construção do direito de autodeterminação do indivíduo; e protege capacidade das pessoas de se relacionarem com o mundo exterior. A partir dessa dupla proteção, devem os Estados-Partes do sistema de direitos humanos adotarem medidas para concretização do direito à privacidade em nível nacional, consolidando instrumentos jurídicos próprios.

\section{REFERÊNCIAS}

ASCENSÃO, José de Oliveira. Direito Civil: Teoria Geral. Volume III: Relações e situações jurídicas. Coimbra: Coimbra Editora, 2002, p. 11.

AMARAL, Francisco. Direito Civil: introdução. Rio de janeiro: Renovar. $8^{\mathrm{a}}$ ed. rev., atual e aum. 2014. p. 304.

BARDIN, L. Análise de conteúdo. São Paulo: Edições 70, 2011, 229 p.

BRANDEIS, L. D.; WARREN, S. D. The right to privacy. Harvard Law Review, Cambridge, v. IV, n. 5, 15 dec. 1890. Disponível em:

<http://readingnewengland.org/app/books/righttoprivacy/?l=righttoprivacy>. Acesso em: 21 jun. 2018.

BRASIL. Tribunal de Justiça do RS. Apelação Cível N 70061242012, Décima Câmara Cível, Julgado em 23/10/2014;

BRASIL. Tribunal de Justiça de SP. APELAÇÃO No: 1001989-76.2014.8.26.0020; Comarca: São Paulo; Órgão julgador: $7^{\mathrm{a}}$ Câmara de Direito Privado; Data do julgamento: 12/08/2015; Data de registro: 12/08/2015;

BRASIL. Tribunal de Justiça de ES. APELAÇÃO: 3000288-85.2013.8.26.0180; Comarca: Espírito Santo do Pinhal; Órgão julgador: $2^{\mathrm{a}}$ Câmara de Direito Privado; Data do julgamento: 10/03/2015; Data de registro: 13/03/2015;

BRASIL. Tribunal de Justiça de MG. APELAÇÃO: 0014233-69.2013.8.26.0576; Comarca: São José do Rio Preto; Órgão julgador: $1^{\text {a }}$ Câmara de Direito Privado; Data do julgamento: 10/03/2015; Data de registro: 10/03/2015;

CACHAPUZ, M. C. Intimidade e vida privada no novo Código Civil Brasileiro: uma leitura orientada no discurso jurídico. Porto Alegre: Sergio Antônio Fabris Ed., 2006.

CACHAPUZ, M. C. A construção de um conceito de privacidade, as cláusulas gerais e a 
concreção de direitos fundamentais. In: PONS, M. (Ed.). . Modelos de Direito Privado. São Paulo: 2014. p. 602.

CORTE EUROPEIA DE DIREITOS HUMANOS (1974). Marckx v. Belgium. (Application no. 6833/74). Strasbourg, 13/05/1974.

(1981). Dudgeon v. The United Kingdom. (Application no. 7525/76). Strasbourg, 22/10/1981. (1985). $X$ and $Y v$. The Netherlands. (Application no. 8978/80). Strasbourg, 26/03/1985. (1986). Gillow v. The United Kingdom. (Application no 9063/80). Strasbourg, 24/11/1986. (1987). Leander v. Sweden. (Application no. 9248/81). Strasbourg, 26/03/1987. (1988). Norris v. Ireland. (Application no. 10581/83). Strasbourg, 26/10/1988. (1989). Gaskin v. The United Kingdom. (Application no. 10454/83). Strasbourg, 07/07/1989. (1992). Niemietz v. Germany. (Application no. 13710/88). Strasbourg, 16/12/1992. (1993). Campbell Christie v. The United Kingdom. (Application no. 12383/86). Strasbourg, 30/08/1993.

(1994a). Murray v. the United Kingdom. (Application no. 14310/88). Strasbourg, 28/10/1994. (1994b). Kroon and others v. the Netherlands. (Application no. 18535/91). Strasbourg, 27/10/1994.

(1997a). Camenzind v. Switzerland. (Application no. 21353/93). Strasbourg, 16/12/1997. (1997b). X, Y and Z v. the United Kingdom. (Application no. 21830/93). Strasbourg, 22/04/1997.

(2000). ADT v. The United Kingdom. (Application no. 35765/97). Satrasbourg, 31/07/2000. (2001). Bensaid v. The United Kingdom. (Application no. 44599/98). Strasbourg, 06/02/2001. (2002a). Mikulić v. Croatia. (Application no. 41526/10). Strasbourg, 24/07/2002. (2002b). Schüssel v. Austria. (Application no. 42409/98). Strasbourg, 21/02/2002. (2002c). Fretté v. France. (Application no. 36515/97). Strasbourg, 26/02/2002. (2005). Ünal Tekeli v. Turkey. (Application 29865/96). Strasbourg, 16/11/2005. (2006). Van der Velden v. the Netherlands. (Application no 29514/05). Strasbourg, 07/12/2006.

(2007a). Tysiac v. Poland. (Application no. 5410/03). Strasbourg, 20/03/2007. (2007b). K.H and others v. Slovakia. (Application no. 32881/04). Strasbourg, 28/07/2007. (2007c). Dickson v. The United Kingdom. (Application no. 44362/04). Strasbourg, $04 / 12 / 2007$.

(2007d). L. v. Lithuania. (Application no. 27527/03). Strasbourg, 14/12/2007. (2008). S. and Marper v. The United Kingdom. (Application nos. 30562/04 and 30566/04). Strasbourg, 04/12/2008. (2009). Petrina v. Romania. (Application no. 78060/01). Strasbourg, 14/10/2009. (2010a). Gillan and Quinton v. The United Kingdom. (Application no. 4158/05). Strasbourg, $12 / 01 / 2010$.

(2010b). A, B and C v. Ireland. (Application no. 25579/05). Strasbourg, 16/12/2010. (2010c). Uzun v. Germany. (Application no. 35623/05). Strasbourg, 18/12/2010. (2011a). Haas v. Switzerland. (Application no 31322/07). Strasbourg, 20/01/2011. (2011b). Mennesson v. France. (Application no 65192/11). Strasbourg, 04/03/2011. (2012a). Von Hannover v. Germany. (Application no. 59320/00). Strasbourg, 24/06/2012. (2012b). Nada v. Switzerland. (Application no 10593/08). Strasbourg, 04/08/2012. (2013). Michaud v. France. (Application no. 12323/11). Strasbourg, 06/03/2013. (2014). Dubská and Krejzová v. The Czech Republic. (Application no. 28859/11 and 28473/12). Strasbourg, 11/12/2014.

(2015a). Y.Y v. Turkey. (Application no. 14793/08) Strasbourb, 10/06/2015. (2015b). Elberte v. Latvia. (Application no. 61243/08) Strasbourg, 05/12/2015. 
CORTE INTERAMERICANA DE DIREITOS HUMANOS (2006). Ximenes Lopes v. Brazil. Preliminary Objection. Series C No. 139. 30/11/2006. (2007). Chaparro Álvarez and Lapo Íñiguez. v. Ecuador. Preliminary Objections, Merits, Reparations and Costs. Series C No. 170. Costa Rica, 21/11/2007. (2010). Rosendo-Cantú et al. v. Mexico. Preliminary Objection, Merits, Reparations, and Costs. Series C No. 216. Costa Rica, 21/08/2010.

(2011). Gelman v. Uruguay. Merits and Reparations. Series C No. 221. Costa Rica, 24/02/2011.

(2012). Atala Riffo and daughters v. Chile. Merits, Reparations and Costs. Series C No. 239. Costa Rica, 24/02/2012. (2012b). Artavia Murillo et al. ("In vitro fertilization") v. Costa Rica. Preliminary Objections, Merits, Reparations and Costs. Series C No. 257., 28/11/2012.

DEPARTMENT OF INTERNATIONAL LAW OF AMERICAN STATES. Comparative study: data protection in the americas. Washington. 2012. Disponível em: http://www.oas.org/es/sla/ddi/docs/CP-CAJP-3063-12_en.pdf

DONEDA, D. Da privacidade à proteção de dados pessoais. Rio de Janeiro: Renovar, 2006.

EUROPE, C. Convenção para a Proteção dos Direitos do Homem e das Liberdades Fundamentais. Roma, 1950. Disponível em: http://www.echr.coe.int/Documents/Convention_POR.pdf.

HABIBUL, Haque Khondker, "Glocalization as Globalization: Evolution of a Sociological Concept". Bangladesh e-Journal of Sociology. Vol. 1. N 2. Jul., 2004.

HUBMANN, Heinrich. Das persönlichkeitsrecht. Münster: Böhlau-Verlag, 1953, p. 30-40.

INTER-AMERICAN JURIDICAL COMMITTEE. Proposed Statement of Principles for Privacy and Personal Data Protection in the Americas. Rio de Janeiro, Brazil, 2012. Disponível em: http://www.oas.org/en/sla/iajc/docs/INFOANUAL.CJI.2012.ENG.pdf.

MAZZUOLI, Valerio de Oliveira. Tratados internacionais dos Direitos Humanos, (pp. 956 a 982), in Curso de Direito Internacional Público, $5^{\text {a }}$. edição, revista, atualizada e ampliada; Dinah Shelton

OEA. Convenção Americana sobre Direitos Humanos, 1969. Disponível em: http://www.cidh.oas.org/basicos/portugues/c.convencao_americana.htm.

PERLINGIERI, P. O direito civil na legalidade constitucional. Rio de Janeiro: Renovar, 2008, p. 669.

SAMPAIO, J. A. L. Direito à intimidade à vida privada: uma visão jurídica da sexualidade, da família, da comunicação e informações pessoais, da vida e da morte. Belo Horizonte: Del Rey, 1998.

TÉRCIO SAMPAIO. Sigilo de dados: o direito à privacidade e os limites à função fiscalizadora Revista de Direito Brasileira | Florianólopis, SC | v. 25 | n. 10 | p. 200-220 | Jan./Abr. 2020 
do Estado. Revista da Faculdade de Direito da USP, v. v. 88, 1993.

SOUZA, E. N. Merecimento de tutela: a nova fronteira da legalidade no direito civil. Revista de Direito Privado. Volume 58. São Paulo: Revista dos Tribunais, abr-jun/2014

STOLL DE MORAIS, L. et al. Direito de acesso e uso da técnica de fertilização in vitro na perspectiva da Corte Interamericana de Direitos Humanos. Revista de Direito Brasileira, v. 17, n. 7, p. 275, 26 set. 2017.

SZANIAWSKI, E. Direitos de Personalidade e sua tutela. Revista dos Tribunais, São Paulo. $2^{\mathrm{a}}$ Ed. 2005.p 355-356. 